Rentinitiline linges $-\frac{1}{2+3}$

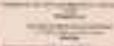
$-=$ $-2=$

\title{
PERSEPSI PEMUSTAKA TERHADAP LAYANAN AMERICAN CORNER DI PERPUSTAKAAN PUSAT UNIVERSITAS HASANUDDIN MAKASSAR
}

\author{
Ayu Trysnawati*
}

Pengutipan: Trysnawati, A. (2016). Persepsi pemustaka terhadap layanan American Corner di Perpustakaan Pusat Universitas Hasanuddin Makassar. Jurnal Ilmu Perpustakaan, Informasi,danKearsipan Khizanah Al-Hikmah, 3(2), 185-.

*Mahasiswa Program Pascasarjana UIN Alauddin Jurusan Konsentrasi Perpustakaan dan Informasi Islam (trysnawati_a@yahoo.com)

\section{ABSTRAK}

American Corner merupakan salah satu bentuk layanan yang ada di Perpustakaan UNHAS. Penelitian ini bertujuan untuk mengetahui persepsi pemustaka terhadap layanan American Corner di Perpustakaan UNHAS. Jenis penelitian ini merupakan jenis penelitian deskriptif kualitatif. Sumber data dalam penelitian ini adalah pemustaka layanan American Corner. Teknik pengumpulan data dilakukan melalui: (1) wawancara, (2) observasi, (3) dokumentasi. Teknik analisis data dalam bentuk reduksi data, penyajian data (data display), dan menarik kesimpulan/verifikasi untuk memperoleh hasil akhir.Berdasarkan hasil penelitian menunjukkan bahwa: (1) Persepsi pemustaka terhadap pelayanan American Corner di Perpustakaan UNHAS sangat baik, layanan yang terdapat pada American Corner membuat pemustaka nyaman berkunjung. (2) Persepsi pemustaka terhadap koleksi American Corner di Perpustakaan Pusat Universitas Hasanuddin Makassar ditanggapi baik oleh pemustaka. Segala hal yang berkaitan dengan koleksi American Corner membuat pemustaka senang berkunjung.

Kata kunci : Amerian Corner, Layanan perpustakaan

\section{ABSTRACT}

American Corner is one of the library services provided by UNHAS Library. This research is aimed to descriptively investigate about users' perception on its service. The data were collected throughout interviews, observations, and documents. Based on the result findings, it is shown that the end-users felt comfortable with its service and enjoying come to the corner. In terms of its collections, the end-users liked to read all materials within the corner.

Keywords: American corner, Library services

\section{PENDAHULUAN}

Perpustakaan sebagai pusat informasi dan masyarakat yang membutuhkan informasi, ibarat dua sisi mata uang yang saling berhubungan yang tak dapat dipisahkan. Hal itu dapat terwujud manakala perpustakaan sudah siap melayani dengan sumber informasi yang memadai, kemudian perpustakaan itu bisa dikelola dengan sebaik-baiknya sementara masyarakat mampu memahami, menghayati, dan menggunakan informasi dalam kesehariannya (Sutarno, 2006:1).

Perpustakaan perguruan tinggi merupakan suatu unsur penunjang yang 
merupakan perangkat kelengkapan di bidang pendidikan, penelitian, dan pengabdian masyarakat. Perpustakaan sebagai sumber daya informasi menjadi tulang punggung gerak majunya suatu institusi khususnya institusi pendidikan dengan adanya tuntutan untuk terus beradaptasi terhadap perkembangan informasi yang sangat cepat dan terus berubah. Hal ini dikarenakan pemustaka dominan dari kalangan akademisi yang memiliki tingkat kebutuhan informasi yang begitu tinggi. Hal demikian mengharuskan perpustakaan terus berupaya mengembangkan layanannya guna memenuhi kebutuhan pemustaka.

\section{Perpustakaan merupakan suatu} tempat untuk memperoleh informasi secara formal maupun non-formal, maka perpustakaan harus menciptakan suatu sistem pelayanan yang sesuai dengan keadaan pemustaka. Sebab kepentingan pemustaka sangatlah penting, apabila suatu perpustakaan tidak diperhatikan maka dengan sendirinya pemustaka akan urungkan niat berkunjung ke perpustakaan karena nilai pelayanan yang kurang baik.

\section{Layanan}

perpustakaan sangat bergantung terhadap pengelola perpustakaan. Pengelola perpustakaan, sebagaimana yang diketahui merupakan pekerja informasi yang bertugas mengolah, menyimpan dan memberikan informasi kepada pemustaka. Agar informasi yang diberikan sampai kepada pemustaka diperlukan sikap dan kemampuan terampil pengelola perpustakaan.

Upaya-upaya yang ditempuh untuk mencapai tujuan itu, salah satunya adalah sikap pengelola perpustakaan yang tanggap/peka dan ramah. Hal ini sangat berperan dalam memberikan layanan kepada pemustaka dan interaksinya dalam perpustakaan. Oleh karena itu yang menjadi persoalan adalah apakah pengelola perpustakaan dapat bersikap melayani dengan baik atau tidak kepada pemustaka. Layanan merupakan salah satu bagian yang sangat penting di perpustakaan karena menjadi ujung tombak untuk memenuhi kebutuhan pemustaka.

Dalam memberikan pelayanan, pengelola wajib bersikap lemah lembut dan niat yang tulus, sebagaimana Allah berfirman dalam QS. Ali-Imran/3:159.

Terjemahan: "Maka disebabkan rahmat dari Allah-lah kamu berlaku lemah lembut terhadap mereka. Sekiranya kamu bersikap keras lagi berhati kasar, tentulah mereka menjauhkan diri dari sekelilingmu. Karena itu maafkanlah mereka, mohonkanlah ampun bagi mereka, dan bermusyawarahlah dengan mereka dalam urusan itu. Kemudian apabila kamu telah membulatkan tekad, maka bertawakkallah kepada Allah, sesungguhnya Allah menyukai orang-orang yang bertawakkal kepada-Nya".

Ayat di atas merupakan wahyu yang diturunkan Allah Swt kepada Nabi Muhammad Saw ketika Perang Uhud. Dari sana dapat kita ambil hikmah jika dikaitkan dengan layanan perpustakaan, yaitu di mana pengelola sangat perlu untuk menerapkan sikap lemah lembut kapan dan di manapun dalam melayani pemustaka.

Salah satu hal yang dapat meningkatkan kunjungan di sebuah perpustakaan yaitu dengan menyediakan berbagai macam layanan di dalamnya. Salah satu contoh yang paling sering kita jumpai saat ini yaitu layanan-layanan corner pada setiap perpustakaan perguruan tinggi. Seperti contohnya 
American corner, Korean corner, Islamic corner, dan lain sebagainya.

Perpustakaan Pusat Universitas Hasanuddin adalah Perpustakaan Peguruan Tinggi dan berstatus sebagai Unit Pelaksana Teknis (UPT). Pada observasi awal penelitian, terdapat satu bentuk layanan yang menarik peneliti untuk mencari tahunya, yaitu American Corner.

\section{RUMUSAN MASALAH}

Berdasarkan uraian yang dikemukakan di atas, maka dapat dirumuskan masalah yang hendak diteliti yaitu bagaimana bentuk layanan American Corner di Perpustakaan Universitas Hasanuddin Makassar?.

\section{TUJUAN DAN MANFAAT PENELITIAN}

\section{a. Tujuan Penelitian}

Mengacu kepada permasalahan penelitian tersebut, tujuan yang hendak dicapai melalui penelitian ini adalah untuk mengetahui bentuk layanan American Corner di Perpustakaan Universitas Hasanuddin.

\section{b. Manfaat Penelitian}

Penelitian ini diharapkan dapat:

1) dijadikan sebagai sumber pemikiran bagi pengembangan ilmu perpustakaan dalam meningkatkan layanan dan penggunaan koleksi American Corner.

2) menjadi rujukan bacaan bagi pengelola layanan dan juga kepada para peneliti selanjutnya yang tertarik untuk mengkaji aspek lain dalam layanan tersebut.

\section{TINJAUAN TEORETIS}

\section{a) Pengertian Persepsi}

Persepsi adalah suatu proses pengenalan atau indentifikasi sesuatu dengan menggunakan panca indra dan keseluruhan individu yang menjadi objek atau sumber data penelitian (Poerwadarminta, 2003: 746). Kesan yang diterima individu sangat tergantung pada seluruh pengalaman yang peka diperoleh melalui proses berpikir dan belajar, serta dipengaruhi oleh faktor yang berasal dari dalam diri individu.

Persepsi adalah suatu proses membuat penilaian atau membangun kesan mengenai berbagai macam hal yang terdapat di dalam lapangan penginderaan seseorang. Persepsi pada hakekatnya adalah proses kognitif yang di alami setiap orang ketika berusaha memahami persepsi berusaha memahami informasi yang diterimanya. Kunci untuk memahami persepsi adalah terletak pada pengenalan bahwa persepsi itu merupakan suatu penafsiran yang unik terhadap situasi, dan bukannya suatu pencatatan yang benar terhadap situasi (Krech, 1962:20).

Persepsi ini dapat dikaji dengan berbagai cara, tetapi dalam ilmu perilaku khususnya psikolog, istilah ini dipergunakan untuk mengartikan perbuatan yang lebih dari sekedar mendengarkan, merasakan, atau merasakan sesuatu. Persepsi yang signifikan itu ialah jika diperluas di luar jangkauan lima indera, dan merupakan suatu unsur yang penting di dalam 
penyesuaian perilaku manusia (Duncan, 1981:109).

\section{Persepsi pemustaka}

Pemustaka merupakan sebutan untuk orang yang memanfaatkan perpustakaan. Istilah pemustaka baru digunakan setelah disahkannya UU RI No. 43 Tahun 2007 tentang perpustakaan. Menurut UndangUndang Nomor 43 Tahun 2007 pasal 1 ayat 9 adalah pengguna perpustakaan yaitu perseorangan, kelompok orang, masyarakat, atau lembaga yang memanfaatkan fasilitas layanan perpustakaan.

Persepsi pemustaka secara singkat dapat diartikan sebagai sebuah penilaian atau kesan seseorang atau sekelompok orang terhadap suatu layanan perpustakaan, yang mana dalam hal ini yaitu layanan American Corner di UPT Perpustakaan Unhas.

\section{b) Pengertian Layanan}

Secara umum, layanan merupakan sarana penghubung antara jasa yang ditawarkan oleh pengelola perpustakaan dengan perlakuan yang diterima oleh pemustaka. Artinya salah satu titik hubung terpenting antara pengelola dan pemakai jasa perpustakaan adalah layanan itu sendiri. Menurut Dian Sinaga dalam Prastowo (2012:41), layanan perpustakaan adalah usaha untuk mendayagunakan bahan-bahan agar bagaimana setiap bahan yang tersedia diperpustakaan dapat dimanfaatkan secara maksimal oleh pemakainya, khususnya masyarakat yang harus dilayani.

Rahayuningsih (2007:85) menyatakan bahwa layanan adalah kegiatan memberikan informasi kepada pengguna perpustakaan dengan memberikan prinsip-prinsip dasar. Dari beberapa pendapat diatas dapat disimpulkan bahwa layanan perpustakaan adalah seluruh kegiatan pelayanan yang berupa pemberian informasi dan fasilitas perpustakaan kepada pengguna untuk memberikan kemudahan kepada pemustaka hanya saja sistem layanan yang digunakan ditiap-tiap perpustakaan berbeda-beda.

\section{American Corner}

American corner merupakan salah satu bentuk layanan yang dapat dijumpai di UPT Perpustakaan Unhas. Layanan ini menyediakan koleksi-koleksi yang beragam seperti buku-buku, koleksi digital, terbitan berkala yang berisikan tentang sosial-politik Amerika, ekonomi Amerika, budaya dan bahasa di Amerika, dan lain sebagainya. Amerinca corner ini diresmikan langsung oleh Rektor Unhas pada tanggal 12 November 2015 (gosulsel.com).

Layanan corner ini, selain menyediakan koleksi-koleksi bacaan, juga sebagai sarana untuk mebuka wawasan mengetahui konsep pendidikan yang ada di Amerika serta sebagai media konsultasi bagi mahasiswa yang tertarik untuk mengetahui beasiswa dalam dan luar negeri, khususnya yang ingin belajar di Amerika.

\section{METODOLOGI PENELITIAN}

\section{a. Jenis Penelitian}

Penelitian ini merupakan penelitian deskriptif kualitatif. Metode kualitatif adalah metode penelitian yang dimaksudkan untuk memahami fenomena tentang apa yang dialami subjek penelitian secara holistik dengan 
cara mendeskripsikan dalam format katakata dan bahasa, pada suatu konteks khusus yang dialami dan dengan memanfaatkan berbagai metode alamiah (Moelong, 2006: 6).

\section{b. Sumber Data}

Subjek penelitian sekaligus yang menjadi sumber utama (informan) pada penelitian ini adalah pemustaka yang berkunjung di layanan American Corner.

\section{c. Teknik Pengumpulan Data}

Pengumpulan data dilakukan dengan cara observasi, wawancara, dan juga dokumentasi.

\section{d. Instrumen Penelitian}

Instrumen penelitian dalam metode kualitatif adalah peneliti itu sendiri. Peneliti berfungsi menetapkan fokus penelitian, memilih informan sebagi sumber data, melakukan pengumpulan data, menilai kualitas data, analisis data, dan menafsirkan data dan membuat kesimpulan atas semuanya. Selain itu, ada beberapa instrumen pendukung yaitu, dokumen, pedoman wawancara dan catatan observasi.

\section{e. Teknik Analisis Data}

Data-data yang telah diperoleh di lokasi penelitian melalui informan dan dokumentasi selanjutnya akan dianalisa dengan teknik analisis data kualitatif dengan cara yaitu reduksi data, penyajian data dan kesimpulan atau verifikasi.

\section{a. Sekilas tentang American Corner di UPT Perpustakaan Unhas}

American Corner didirikan pertama kali di Rusia pada tahun 2000. American Corner meningkat setidaknya 28 negara termasuk Eropa, Asia dan Afrika. Di Indonesia sendiri, terdapat 10 Perguruan Tinggi yang memiliki koleksi American Corner. Adapun 10 Perguruan Tinggi yaitu: UIN Syarif Hidayatullah Jakarta, Universitas Airlangga, Universitas Muhammadiyah Yogyakarta, Universitas Gajah Mada, UMM, IAIN Medan, IAIN Semarang, Universitas Indonesia, Universitas Hasanuddin, Universitas Sumatera Utara.

American Corner adalah suatu media yang diprogramkan oleh seksi Hubungan Masyarakat (Public Affair Section) Keduataan Besar Amerika Serikat di Washington DC, Amerika Serikat. American Corner adalah program kemitraan antara Public Affairs Kantor Kedutaan Besar Amerika Serikat di Indonesia. Layanan ini adalah pusat informasi yang merupakan hasil kerja sama Universitas Hasanuddin dengan Kedutaan Besar Amerika Serikat di Jakarta. Kerja sama ini dimaksudkan agar kedua belah pihak dapat saling memahami perbedaan sosial budaya negara dan bangsa Amerika Serikat dengan Indonesia. American Corner mulai beroperasi pada tahun 2005 tepatnya pada tanggal 14 November 2005 dan terbuka untuk masyarakat umum. Layanan ini menyediakan berbagai macam sumber informasi, semua koleksi di American Corner hanya dapat dibaca di tempat saja dan difotokopi.

\section{HASIL PENELITIAN DAN PEMBAHASAN}




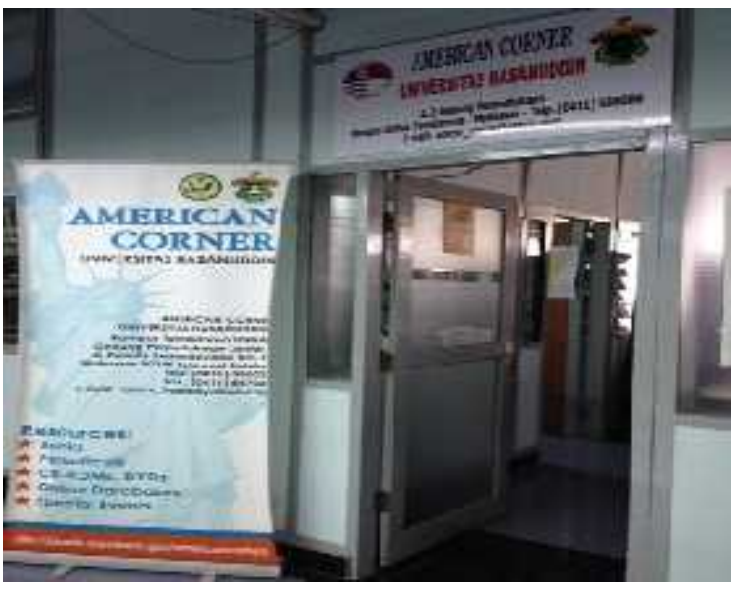

Gambar 1. Pintu masuk ke layanan American Corner di UPT Perpustakaan Unhas Makassar
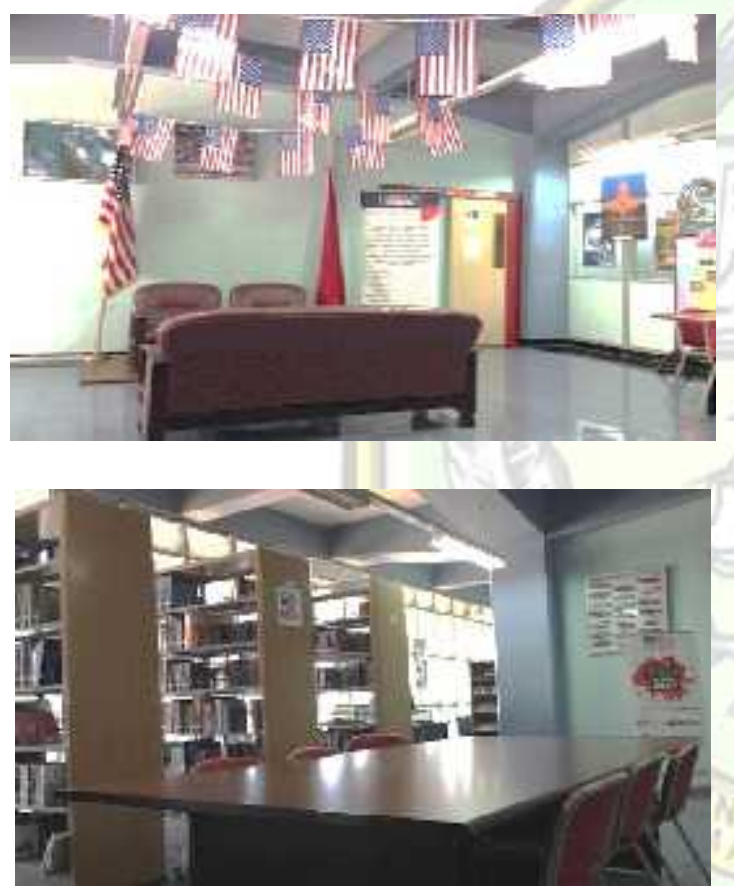

Gambar 2. Ruang baca American Corner

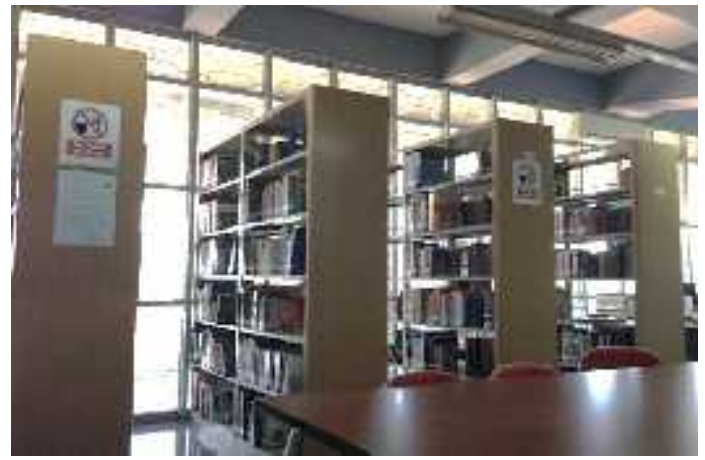

Gambar 3. Rak dan Koleksi American Corner di Perpustakaan Pusat Universitas Hasanuddin Makassar

b. Persepi pemustaka terhadap layanan

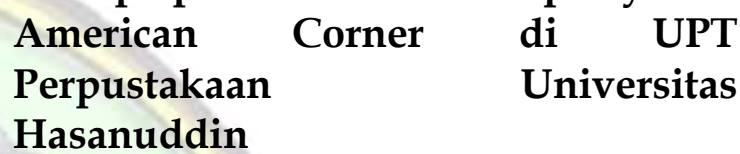

Pelayanan prima merupakan hal yang penting untuk diketahui bagi tiap-tiap perpustakaan. Sebagaimana yang kita ketahui bersama bahwa perpustakaan merupakan salah satu lembaga yang bergerak dalam bidang jasa pelayanan. Layanan American corner merupakan salah satu bentuk layanan yang ada dari jenis-jenis layanan lainnya di UPT Perpustakaan Unhas. Berikut ini akan diuraikan hasil wawancara dari beberapa informan yang menggunakan layanan tersebut.

Layanan American corner menjadi salah satu spot yang menarik perhatian pengunjung UPT Perpustakaan Unhas. Dari observasi awal, ruang layanan ini telah didesain sebaik mungkin demi kenyamanan para pengunjungnya. Beberapa pengunjung menyatakan bahwa mereka senang di dalam layanan tersebut, karena menambah wawasan mereka tentang hal-hal yang baru, khususnya yang berkaitan dengan pendidikan antar bangsa.

Tidak sedikit pengunjung yang datang memanfaatkan koleksi-koleksi tersebut, 
terutama pada masa-masa aktif perkuliahan.

Pelayanan pada American Corner sudah sangat baik, baik dalam hal tutur sapa dalam memberi petunjuk layanan koleksi American Corner, keramahan dalam memberikan layanan, cara pengelola berkomunikasi dengan pemustaka, penjelasan yang diberikan mengelola dalam melayani, cukup lengkap dan sesuai dengan yang dibutuhkan, penguasaan pengelola terhadap layanan American Corner, kecepatan pengelola menanggapi pemustaka dan perhatian pengelola terhadap pemustaka yang datang berkunjung sudah sangat baik.

Begitu juga dengan pemberian layanan sejak pertama kali datang, kesediaan pengelola untuk menanggapi permintaan pemustaka pada koleksi American Corner. Pelayanan yang diberikan oleh pengelola membuat pemustaka senang berkunjung dan dapat dengan mudah menemukan koleksi yang diinginkan oleh pemustaka.

Koleksi merupakan media informasi bagi pemustaka. Koleksi yang dimaksud di sini adalah koleksi American Corner yang ada di Perpustakaan Pusat Universitas Hasanuddin. Koleksi yang terdapat pada American Corner ditanggapi baik oleh pemustaka. Baik dari segi jumlah koleksi yang tersedia, kerapian penataan koleksi, kondisi fisik koleksi yang masih layak pakai, koleksi buku, majalah, CD dan DVD mengikuti perkembangan/uptodate dan juga koleksi yang tersedia relevan atau sesuai dengan kebutuhan mahasiswa. Sesuai dengan hasil wawancara penulis dapat memberikan gambaran bahwa pada proses pemberlakuan kartu anggota perpustakaan terdapat pendapat yang pro dan kontra. Hasil wawancara tersebut menunjukkan bahwa proses pemberlakuan kartu cukup baik, sedangkan hasil yang lain yaitu membuktikan bahwa pemustaka yang berkunjung ke perpustakaan benar-benar memanfaatkan koleksi American Corner untuk mencari informasi yang diinginkan. Hal ini dapat menjadi pertimbangan bagi pengelola untuk menunjang kemudahan akses pemustaka.

\section{KESIMPULAN DAN SARAN}

\section{a. Kesimpulan}

Setelah melakukan penelitian tentang persepsi pemustaka terhadap layanan American Corner, maka peneliti memperoleh beberapa kesimpulan yaitu:

1) Persepsi pemustaka terhadap pelayanan American Corner di Perpustakaan Uviversitas Hasanuddin, berdasarkan penelitian pada layanan koleksi American Corner sudah sangat baik. Hal-hal yang berkaitan dengan layanan koleksi American Corner ditanggapi dengan baik oleh pemustaka. Layanan yang terdapat pada koleksi American Corner membuat pemustaka senang berkunjung.

2) Persepsi pemustaka terhadap koleksi American Corner di Perpustakaan Pusat Universitas Hasanuddin, berdasarkan penelitian pada koleksi American Corner ditanggapi dengan baik oleh pemustaka. Segala hal yang berkaitan dengan koleksi American Corner membuat pemustaka senang berkunjung.

\section{b. Saran}


Adapun saran-saran yang dapat diberikan oleh penelitian yaitu sebagai berikut.

a. Pertahankan senyum, salam dan sapa pengelola kepada pemustaka

b. Diperlukan untuk meningkatkan terus pelayanan pada koleksi American Corner

c. Diharapkan untuk meningkatkan perhatian pengelola kepada pemustaka saat memanfaatkan layanan American Corner

d. Diharapkan agar pengelola selalu datang tepat waktu

e. Pengelola diharapkan untuk meningkatkan kecepatan dan ketanggapan dalam melayani pemustaka.

\section{DAFTAR PUSTAKA}

Achmad, dkk. 2012. Layanan Prima: Perwujudan Layanan Prima ${ }^{++}$ Perpustakaan. Jakarta: Sagung seto.

Afida, Ana. 2011. Sikap Pemustaka Terhadap Layanan American Corner di Perpustakaan: Studi Kasus di Perpustakaan IAIN Walisongo Semarang. Tesis, Depok: Fakultas Ilmu Pengetahuan Budaya, Universitas Indonesia.

Almah, Hildawati. 2012. Pemilihan dan Pengembangan Koleksi Perpustakaan. Makassar: Alauddin University Press.

Arikunto, Suharsimi. 2002. Prosedur Penelitian. Jakarta : PT Reneka Cipta.

------. 2007. Prosedur Penelitian suatu Pendekatan Praktik. Jakarta: PT Reneka Cipta.

Azmi Nur Widya. 2013. Persepsi pemustaka tentang Sikap Pustakawan pada Layanan Sirkulasi di Perpustakaan Daerah Jepara. Skripsi
SarjanaFakultas Ilmu Budaya

Universitas di Ponegoro, Semarang. Azwar, Saifuddin. 2000. Sikap Manusia: Teori dan Pengukurannya. Yogyakarta: Pustaka Pelajar Offset. Bogdan dan Taylor dalam Lexy J. Moleong. 2010. Metodologi Penelitian Kualitatif. Bandung: Remaja Rosdakarya.

Duncan, W.Jack. 1981. Organizational Behavior. Ed.2; Boston: Hougton Mifflin.

F. Rahayuningsih. 2007. Pengelolaan Perpustakaan. Yogyakarta: Graha Ilmu.

Faisal, Sanapsiah. 2001. Format-format Penelitian Sosial. Jakarta: Raja Grafika Persada.

Gosulsel.com

(http://gosulsel.com/psm/12/11/ 2015/launching-american-cornerdi-perpustakaan-unhas/)

Hermawan S, Rachman. 2006. Etika Kepustakawan. Jakarta: Sagung Seto. Indonesia. Departemen Agama. 2008. AlQur'an Dan Terjemahannya. Bandung: Diponegoro.

Jafar, Farida. 2005. Manajemen Jasa : Pendekatan Terpadu. Jakarta: Ghalia Indonesia.

Krech, David. 1962. Individual in Society.New York: McGraw-Hill.

Luthans, Fred. 1981. Organizational Behavior. Ed. 2; New York: McGraw-Hill.

Moelong Lexy, 2006. Metode Penelitian Kualitatif. Edisi Revisi. Bandung: Remaja Rosdakarya.

Muaffaq N, Ahmad. 2014. Tafsir Ilmu Perpustakaan. Cet.I; Makassar: Alauddin University Press.

Muin, Muh. Azwar. 2014. Information Literacy Skills: StrategiPenelusuran Informasi Online. Makassar: Alauddin University Press. 
Mulyadi, Irvan. 2013. Dasar-Dasar Kepustakawanan. Cet.I; Makassar: Alauddin University Press.

Nusantari, Anita. 2012. Strategi Pengembangan Perpustakaan. Jakarta: Prestasi Pustaka.

Poerwadarminta. 2003. Kamus Bahasa Indonesia. Ed. 3; Jakarta: Balai Pustaka.

Republik Indonesia. 2007. “Undangundang R.I. Nomor 43 Tahun 2007 tentang Perpustakaan. Yogyakarta : Pustaka Mahardika.

Rosalin, Elin. 2008. Pemanfaatan Perpustakaan dan Sumber Informasi. Bandung: Karsa Mandiri Persada.

Sarwono, 2006. Psikologi Remaja. Jakarta: Raja Grafindo Persada.

Sugiyono. 2006. Memahami Penelitian Kualitatif. Bandung: Alfabeta.

-------. 2013. Metode Penelitian Kualitatif, Kualitatif dan RED. Bandung: Alfabeta.

Sutarno, NS. 2006. Manajemen Perpustakaan: Suatu Pendekatan Praktik. Jakarta : Sagung Seto.

Shihab, M.Quraisy. 2002. Tafsir al-Misbah :

Pesan, kesan, dan keserasian al Qur'an.Jakarta : Lentera Hati.

Soeatminah. 1992. Perpustakaan, Kepustakaan dan Pustakawan. Yogyakarta: Kanisius.

Suhayarto. 2014. Mengenal dan Mengelola Perpustakaan.Yogyakarta:

Naafi'BookMedia.

Suherman. 2013. Perpustakaan Sebagai Jantung Sekolah: Referensi Pengelolaan Perpustakaan Sekolah.Bandung: LITERATE.

Suwarno, Wiji. 2010. Dasar-Dasar Kepustakaan. Bogor: Ghalia Indonesia. 2010. Dasar-Dasar Ilmu Perpustakaan. Yogyakarta: Ar-Ruzz.
2009. Psikologi Perpustakaan. Cet. I; Jakarta: Sagung Seto.

Qalyubi, Syihabuddin. 2007. Dasar-dasar Ilmu Perpustakaan dan Informasi. Yogyakarta: Jurusan Ilmu Perpustakaan dan Informasi Fakultas Adab IAIN Sunan Kalijaga.

Thoha, Miftah. 2002. Perilaku Organisasi: Konsep Dasar dan Aplikasinya. Ed.I. Jakarta : Raja Grafindo Persada.

Universitas Hasanuddin. 2009. Memorandum of Understanding Between The Public Affairs Section The U.S Embassy Jakarta And UniversitaS Hasanuddin. 